\title{
Triamcinolone acetonide for rare ocular manifestations of pemphigus vulgaris: a case report
}

This article was published in the following Dove Press journal:

Clinical Ophthalmology

14 April 2010

Number of times this article has been viewed

\author{
N Kozeis' \\ S Tyradellis' \\ E Dragiotis' \\ $\mathrm{H}$ Eleftheriadis ${ }^{2}$ \\ 'Department of Ophthalmology, \\ Hippokration Hospital of Thessaloniki, \\ Greece; ${ }^{2}$ Southend Hospital NHS \\ Trusts, Westcliff-on-Sea, Essex, UK
}

\begin{abstract}
We present an interesting case of pemphigus vulgaris with severe and rare eye manifestations. An old lady with systemic and ocular manifestations of pemphigus vulgaris was treated with systemic corticosteroids and immunosuppressants, with no effect. Subconjunctival injection of triamcinolone acetate reduced the ocular signs and led to gradual reduction of the systemic medications.
\end{abstract}

Keywords: pemphigus vulgaris, ocular manifestations, triamcinolone acetate

\section{Introduction}

Pemphigus vulgaris (PV) is an uncommon (0.5-3.2 cases per 100,000), potentially life-threatening (5\%-15\%), autoimmune bullous mucocutaneous disease, ${ }^{1}$ which can rarely affect the eyes. Autoantibodies are formed against desmoglein, the "glue" that attaches adjacent epidermal cells. When autoantibodies attack desmogleins, the cells become separated from each other, a phenomenon called acantholysis. This causes blisters and erosions. ${ }^{2,3}$

We present a case of a patient with ocular manifestations of PV resistant to systemic and topical medication, which was successfully treated with subconjunctival injections of triamcinolone acetonide (TA).

\section{Case report}

A 76-year-old woman, suffering from PV, was referred to our department due to acute onset of intense burning and foreign body sensation in her right eye, despite her treatment with systemic methylprednisolone $15 \mathrm{mg} /$ day and azathioprine $100 \mathrm{mg}$ /day due to PV. PV was diagnosed clinically and by performing (a) histopathology from the edge of a blister, (b) direct immunofluorescence (DIF) on normal-appearing perilesional skin, and (c) indirect immunofluorescence (IDIF). Acantholytic cells were found in a Tzanck smear, taken from the base of an erosion, which helped to differentiate PV from pemphigus foliaceous.

Her best corrected visual acuity was $6 / 9$ bilaterally. Slitlamp examination revealed pronounced conjunctival hyperaemia, mucus secretions, ulcerative erosions involving the palpebral conjunctiva at the right lower eyelid margin (Figure 1) and punctate corneal epithelial erosions involving the inferior part of the cornea of the same eye. Schirmer's test without anesthetic was markedly reduced $(3 \mathrm{~mm})$ as well as the tear break up time (BUT) (3 seconds).

The disease was considered uncontrolled due to the appearance of new symptoms and signs. Therefore the dose of methylprednisolone was increased to $40 \mathrm{mg} / \mathrm{day}$,
Correspondence: Nikolaos Kozeis

8 Kouskoura Str, 54622

Thessaloniki, Greece

Tel +302310270650

Email nkozeis@med.auth.gr 


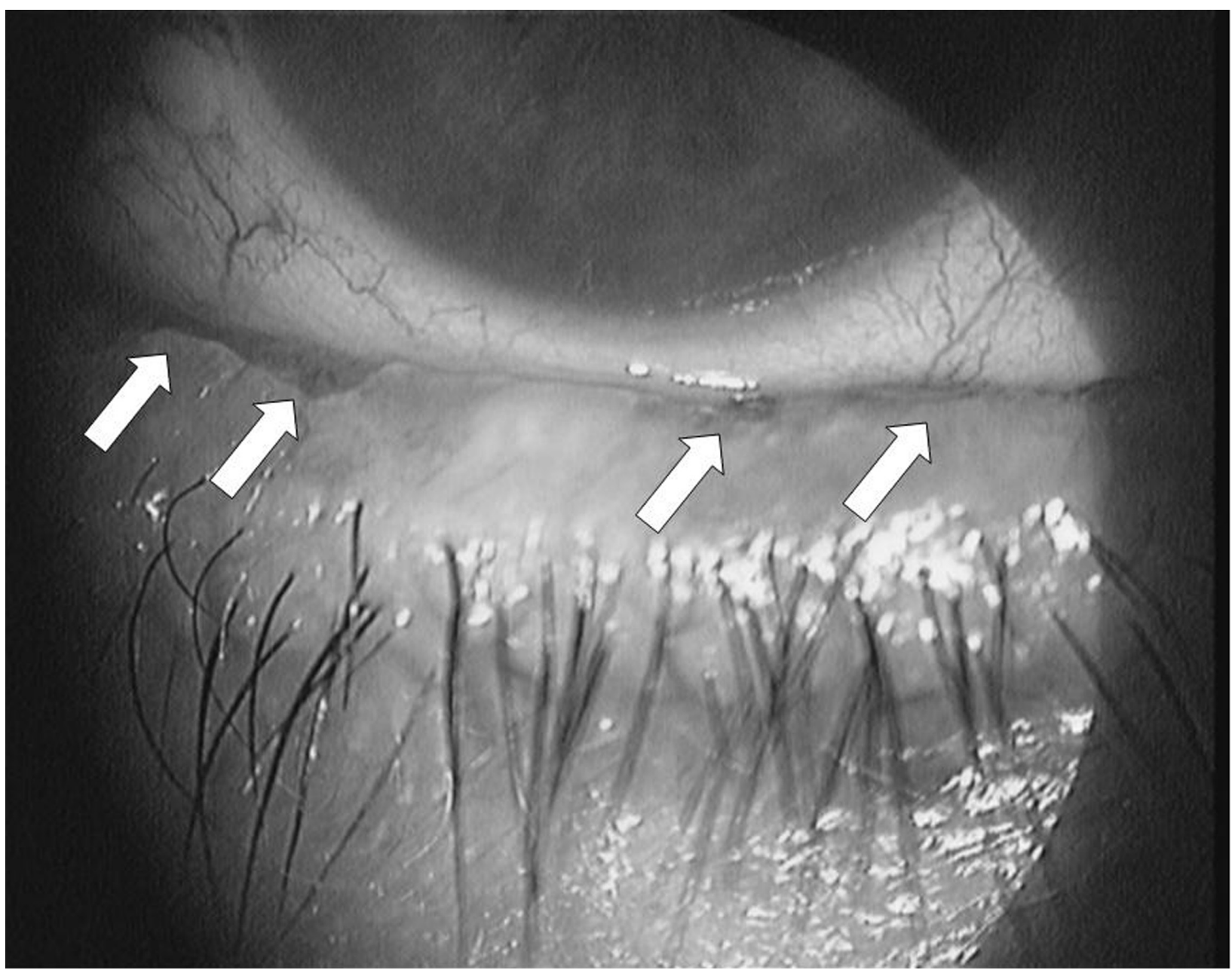

Figure I The right eye of the patient with pemphigus vulgaris: Ulcerative erosions can be seen at the palpebral conjunctiva at the lower eyelid margin.

and the azathioprine was replaced by cyclophosphamide $100 \mathrm{mg}$ daily. In addition, the patient was treated with topical dexamethasone $0.1 \%$ daily and frequent instillation of unpreserved carbomer $0.3 \%$. This therapeutic regime was applied for 2 months without symptomatic improvement. Hence, a subconjunctival injection of TA $20 \mathrm{mg}$ in $0.5 \mathrm{~mL}$ (Kenacort $^{\circledR} 40 \mathrm{mg} / \mathrm{mL}$; Bristol-Myers Squibb) was given after informed consent was obtained, but without stopping the systemic treatment. There were no adverse effects of TA noted at any time. Two weeks following the TA injection the patient's symptoms were reduced significantly - the eye was less inflamed and the conjunctival ulcers were reduced in size. Due to the initial positive response to the TA injection a second injection was given at that time. Three months later the symptoms had improved significantly and the ulcers had disappeared (Figure 2), enabling us to taper further the systemic treatment. The Schirmer's test was also increased to $6 \mathrm{~mm}$ as well as the BUT was prolonged to 6 seconds. One year after the second injection the patient is still asymptomatic without signs of recurrence.

\section{Discussion}

Ocular pemphigus is probably underdiagnosed and its frequency appears underestimated. ${ }^{3} \mathrm{PV}$ is recognized by a dermatologist from the appearance and distribution of the skin lesions. Definitive diagnosis requires examination of a skin biopsy from the edge of a blister by a pathologist. The pathologist looks for an intraepidermal vesicle caused by acantholysis. Definitive diagnosis also requires the demonstration of anti-desmoglein autoantibodies by direct immunofluorescence on the skin biopsy. These antibodies appear as IgG deposits along the desmosomes between epidermal cells, a pattern reminiscent of chicken wire. Anti-desmoglein antibodies can also be detected in a blood sample using the ELISA technique. A high titer of cANCA is claimed to be an important feature of the disease. ${ }^{3,4}$ 


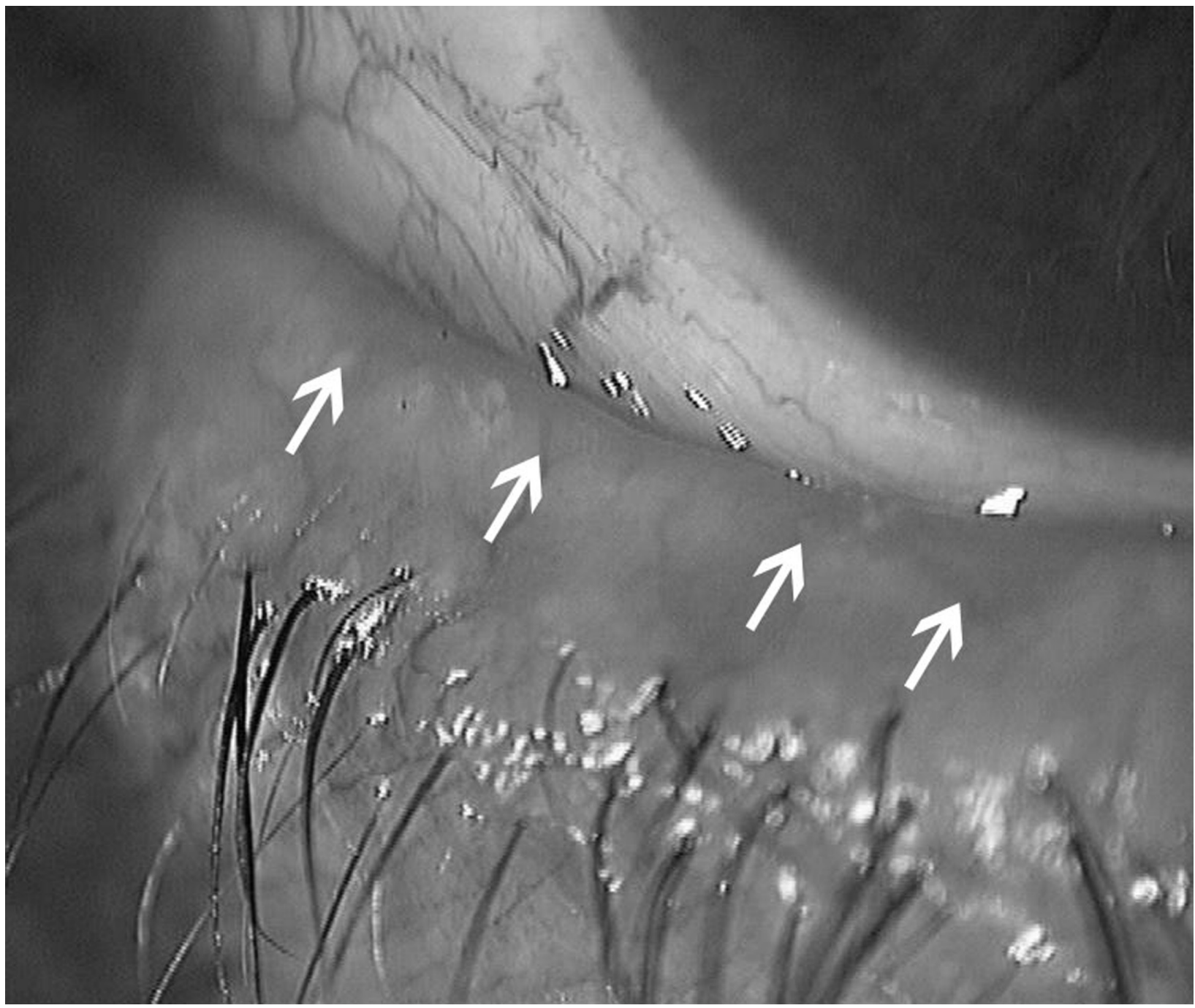

Figure 2 The lid margin 3 months after the second subconjunctival injection of triamcinolone acetonide. No erosions are seen at the palpebral conjunctiva of the right lower eyelid margin.

Ocular involvement with PV is very rare. ${ }^{2}$ The most characteristic findings are conjunctival hyperemia, conjunctivitis, eye irritation and mucus secretions. ${ }^{5}$ Catarrhal conjunctivitis is very common in PV, while bullae and conjunctival erosions are seen rarely. ${ }^{5,6}$ Conjunctival fibrosis is very rare $^{2}$ as is corneal involvement. ${ }^{7}$

The therapeutic approach for the treatment of PV requires a systemic therapy with steroids and immunosuppressive drugs. In our case, neither the increase of the initial systemic doses, nor the replacement of azathioprine by cyclophosphamide, had any effect on the ocular signs of the disease. Even topical steroids (drops) and lubricants were used, but with no symptomatic effect, probably due to persistent erosion of the lid margins, affecting the quality of the tear film and further causing severe dryness of the eye. A considerable improvement was seen following
2 subconjunctival injections of TA $20 \mathrm{mg}$ with an interval of 2 weeks, probably due to "normalization" of the lid margin anatomy, which improved ocular surface dryness. The improvement of the clinical condition led to the tapering of the systemic treatment. The subconjunctival TA injections provided sustained release of steroids at the side of greatest need, ie, the palpebral conjunctiva, with no systemic adverse effects. This was of particular importance in our patient who started to present signs of Cushing's syndrome from the long-term use of systemic steroids.

To the best of our knowledge, this is the first reported case of subconjunctival injections of TA for the treatment of ocular manifestations of PV. Daouds et al ${ }^{7}$ reported 11 cases of ocular manifestations of PV treated mainly with systemic steroids, and in 1 case they used TA. The authors concluded that the disease could recur (mean follow up 48.9 months), 
but that finally all patients eventually recovered fully without sequelae. They also found TA a possible modality in unresponsive cases.

In our case, TA proved more helpful. Although no long case series are available, TA could be regarded as an effective alternative for patients with serious ophthalmic manifestations of PV unresponsive to systemic therapy or those with serious adverse effects to systemic treatment.

\section{Disclosures}

The authors report no conflicts of interest.

\section{References}

1. Korman N. Pemphigus. J Am Acad Dermatol. 1988;18:1219-1238.

2. Frith PA, Venning VA, Wojnarowska F, et al. Conjunctival involvement in cicatricial and bullous pemphigoid: a clinical and immunopathological study. Br J Ophthalmol. 1989;73:52-56.
3. Palleschi GM, Giomi B, Fabbri P. Ocular involvement in pemphigus. Am J Ophthalmol. 2007;144(1):149-152.

4. Daoud YJ, Cervantes R, Foster CS, Ahmed AR. Ocular pemphigus. J Am Acad Dermatol. 2005;53(4):585-590.

5. Hodak E, Kremer I, David M, et al. Conjunctival involvement in pemphigus vulgaris: a clinical, histopathological and immunofluorescence study. Br J Dermatol. 1990;123:615-620.

6. Nelson ME, Rennie IG. Symmetrical lid margin erosions: a condition specific to pemphigus vulgaris? Case report. Arch Ophthalmol. 1988;106:1652-1653.

7. Baykal HE, Pleyer U, Sonnichsen K, et al. Severe eye involvement in pemphigus vulgaris. Ophthalmologe. 1995;92:854-857.
Clinical Ophthalmology

\section{Publish your work in this journal}

Clinical Ophthalmology is an international, peer-reviewed journal covering all subspecialties within ophthalmology. Key topics include: Optometry; Visual science; Pharmacology and drug therapy in eye diseases; Basic Sciences; Primary and Secondary eye care; Patient Safety and Quality of Care Improvements. This journal is indexed on

Submit your manuscript here: http://www.dovepress.com/clinical-ophthalmology-journal

\section{Dovepress}

PubMed Central and CAS, and is the official journal of The Society of Clinical Ophthalmology (SCO). The manuscript management system is completely online and includes a very quick and fair peer-review system, which is all easy to use. Visit http://www.dovepress.com/ testimonials.php to read real quotes from published authors. 